\title{
Analysis of a recovery process: Dwingelose Heide revisited
}

\author{
M. Anand ${ }^{1}$ and G. W. Heil \\ Department of Plant Ecology and Evolutionary Biology, Utrecht University PO Box 80084, \\ Utrecht, 3508 TB, The Netherlands \\ ${ }^{1}$ Corresponding author. Current address: Department of Biology, Laurentian University, Ramsey Lake Road, \\ Sudbury, Ontario, Canada, P3E 2C6. Tel.: +1 705-675-1151 Fax: +1 705-675-4859 \\ E-mail: Manand@nickel.laurentian.ca
}

Keywords: Community, Complexity, Pattern, PCA, Permanent plot, Scale, Space, Spatial competition hypothesis, Transition, Vegetation.

\begin{abstract}
The recovery process of a Dutch heathland after fire is investigated. The study area, $12 \mathrm{~m} \times 20 \mathrm{~m}$, has been surveyed yearly between 1963 and 1993. Previous work has shown that a stationary Markov chain models the observed recovery process well. However, the Markov model fails to capture an important observation, the existence of a phase structure. The process begins deterministically, but small random (non-Markov) effects accumulate through time and at some point the process suddenly becomes noisy. Here we make use of the spatial information contained in vegetation maps to examine dynamics at a fine spatial scale. We find that the phases observed at a large spatial scale separate themselves out distinctly at finer spatial scales. This spatial information allows us to investigate hypotheses about the mechanisms governing deterministic versus noisy vegetation dynamics.
\end{abstract}

Abbreviation: PCA - principal component analysis.

\section{Introduction}

Vegetation recovery is considered as compositional change in a plant community following a major perturbation. We use the general term 'recovery' rather than the textbook term 'secondary succession' to avoid association with classical Clementsian theories of vegetation change (Clements 1916, Gleason 1926), as these can limit views about the process and its attractor states. Indeed, it is the fundamental nature of the process and attractor that are emphasized in the present analysis.

Our case study is the recovery of a Dutch heathland, Dwingelose Heide after a fire. Heathland plant communities are well-studied in ecology from various perspectives (Gimingham 1972, Aerts and Heil 1993), in part because they offer a study-system for which the rate of change in species composition, diversity and other system properties is fast enough (but not too fast) to be observed, measured, and contemplated in a reasonable amount of time.
Furthermore, heathland plant communities are relatively simple, with often only three or four plant species dominating community dynamics. It is not surprising that heathlands were one of the first systems studied in relating pattern to process in the plant community (Watt 1947).

The Dwingelose Heide, and in particular the records of J. T. de Smidt (de Smidt 1977) have been the subject for several previous investigations. Lippe et. al. (1985) used a subset of the records to study the applicability of a homogeneous Markov chain model to vegetation dynamics. Their definition of dynamics was based on a timespan of 19 years, and estimates of the relative abundance of species at the spatial scale of the entire permanent plot. They found that a Markov chain model did not fit the observed recovery process, concluding that species-level transitions were time-dependent. In another attempt to formalize the recovery process, Prentice et. al. (1987) constructed a simple simulation model which considered 
the three dominant species, Empetrum nigrum, Erica tetralix and Calluna vulgaris, at the level of the growth of individual plants. The model focussed in great detail on morphological and life-history characteristics of the species. Their model was able to reproduce the overall behaviour of the observed process quite well, suggesting that a mechanistic approach can help to gain insight into the functioning of heathland dynamics. However, their model cannot provide insights about the nature of the process in general since it does not consider species interactions.

Orlóci et. al. (1993) and Anand and Orlóci (1997) used the same data as a case study for testing new analytical techniques and for simulation studies. Using a new method for estimating transition probabilities and hypothesis testing based on randomization testing (Pillar and Orlóci 1997), Orlóci et. al. (1993) demonstated that a homogeneous Markov chain modeled the observed recovery process quite well. Nevertheless, Anand and Orlóci (1997) pointed out that any simple linear model applied to the recovery process fails to capture the existence of a phase structure. The heathland displays transient behaviour: community-level dynamics in the early phase (1963-1971) is more or less linear, but then suddenly breaks down into an extremely 'noisy' phase. Anand and Orlóci (1997) showed that adding small amounts of quasirandom perturbation to the stationary Markov chain model could turn the normally well-behaved dynamics into a deterministically-chaotic one. As such, this perturbed Markov process more closely resembled the transient behaviour of the observed process, and importantly, suggested a very important point about the recovery process in general: sensitive dependence on initial conditions and the presence of a strange attractor (sensu Lorenz 1963). In ecological terms, this would render the recovery process at once deterministic and individualistic, giving importance to the potential for small random effects to amplify in time.

All this previous work focussed on the temporal dynamics of the heathland and did not make full use of the spatial information contained in de Smidt's records. As such, the source of 'randomness' or 'noise', which are almost certainly the outcome of complex fine-scale spatial effects (Czárán and Bartha 1995, van der Maarel 1996, Tilman and Kareiva 1997, Bascompte and Solé 1998), could not be made explicit. However, having fixed a point in time, 'noise' in a system can be assessed in terms of spatial heterogeneity, or in this case, by considering how quadrats within the permanent plot deviate from some expected (e.g., average or typical) behaviour. We thus present an analysis of the heathland recovery process (which now spans a much longer timespan of 30 years) that explicitly recognizes a spatial component.

\section{Materials and methods}

We focus on the Dwingelose Heide, a heathland located in the northeastern Netherlands $\left(52^{\circ} 45^{\prime} \mathrm{N}, 6^{\circ} 5^{\prime} \mathrm{E}\right)$, and specifically on the permanent plot records of J. T. de Smidt (De Smidt 1977). These records track the recovery of a heathland following a severe fire in 1959. The heathland has been grazed by sheep, but since the fire, no other management had been practiced (for more details, see Lippe et. al. 1985). The records of J.T. de Smidt are extraordinary in their extent and detail. Spatially-explicit, (almost) yearly surveys of a permanent plot (12 $\mathrm{m}$ x $20 \mathrm{~m})$

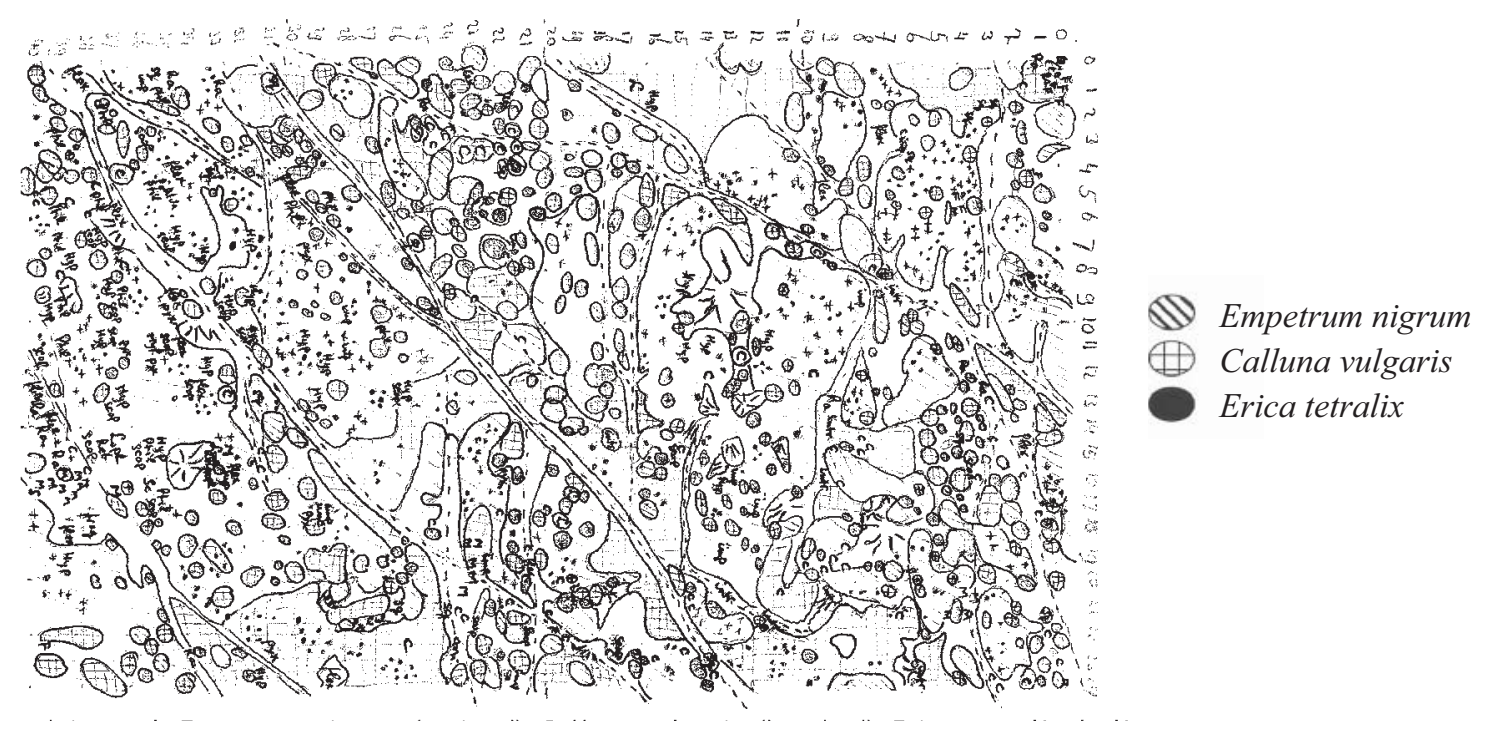

Figure 1. Vegetation map of the heathland in 1973 (10 years after fire). The dimensions are $12 \mathrm{~m}$ x $20 \mathrm{~m}$. The most impressive changes in this period were the decrease in bare ground due to increasing plant cover and the increase of disturbance (emergence of sheep paths). 
were made over a period of 30 years (1963-1993). Vegetation maps of the area were drawn at a resolution (grid size) of $0.5 \mathrm{~m} \mathrm{x} 0.5 \mathrm{~m}$ for the first 15 years, and thereafter at a resolution of $1 \mathrm{mx} 1 \mathrm{~m}$ (see Fig. 1 for an example).

The maps were sampled at the equivalent resolution (quadrat size) of $1 \mathrm{~m} \times 1 \mathrm{~m}$ (scale initially 1:100 and later $1: 25)$. This was the highest resolution at which drawings were considered reliable and the scale at which species interactions can be observed most directly (J. de Smidt, personal communication). Cover abundance of all species and bare ground within a quadrat were estimated. From these, the seven dominant species were retained and other combined in a single group following Lippe et. al. (1985). No data were available for 1987 . We used principal component analysis (PCA) to summarize compositional dynamics. PCA is a widely used method in which the multivariate correlations among species in parameter space are used to build a simplified description of the relationships (Orlóci 1978, see Deutschman et. al. 1997 for a good recent application). PCA was applied to the covariance matrix defined by co-occurrences of species in time, and was performed on each spatial unit (cell size $1 \mathrm{~m} \mathrm{x} 1 \mathrm{~m}$ ).

To observe specifically the rate and direction of recovery, we constructed phase space plots in the tradition of classical dynamical systems theory (Rosen 1970). In order to visualize phase space dynamics, the community was summarized using the Euclidean distance measure between temporal coenostates. Since governing equations are not known, our interpretation of these phase plots was restricted to qualitative observations. To quantify the relationship between initial and final states, we calculated the frequency with which cells similar and different in initial conditions diverged, converged or remained similar or different at the end of the process. Here, similar and different initial and final conditions were established through a classification (single-link clustering) procedure (Orlóci 1978).

We were also interested in quantifying species-level transitions. Since it was extremely difficult to observe actual species replacements, we estimated transition matrices following the method of Orlóci et. al. (1993). This method assumes that losses and gains in species abundance from one year to the next are distributed proportionally in the community, and that the major limiting resource is space (bare ground).

\section{Results}

Figure 2 displays the global pattern of species (only the 3 dominant species, Empetrum nigrum, Calluna vulgaris and Erica tetralix as well as bare ground are graphed) and community-level dynamics of the heathland for the 30 year period. It is clear that the noisy phase continued after 1981 (timestep 19). The drought of 1976 (timestep 14) described by Lippe et. al. (1985) is apparent in the following year.

For the fine-scale analysis, we present only a subset of the map for economy. This is sufficient to illustrate the general trends seen across the entire map. Figure 3a displays the species-level dynamics in a $7 \times 7$ subset of the area at a resolution (cell size) of $1 \mathrm{~m} \mathrm{x} 1 \mathrm{~m}$. It is clear that in most cells, Empetrum dominates dynamics. In a few cells, Calluna manages to become dominant for a sustained period of time, but in most cases this does not last indefinitely. These cells do not occur randomly but in contiguous patches. The dominance of Calluna appears to reflect the failure of initial establishment of Empetrum. Eventually, however, Empetrum invades these areas, but the effect of this invasion varies. In some cases Empetrum completely overtakes Calluna, but in others this does not
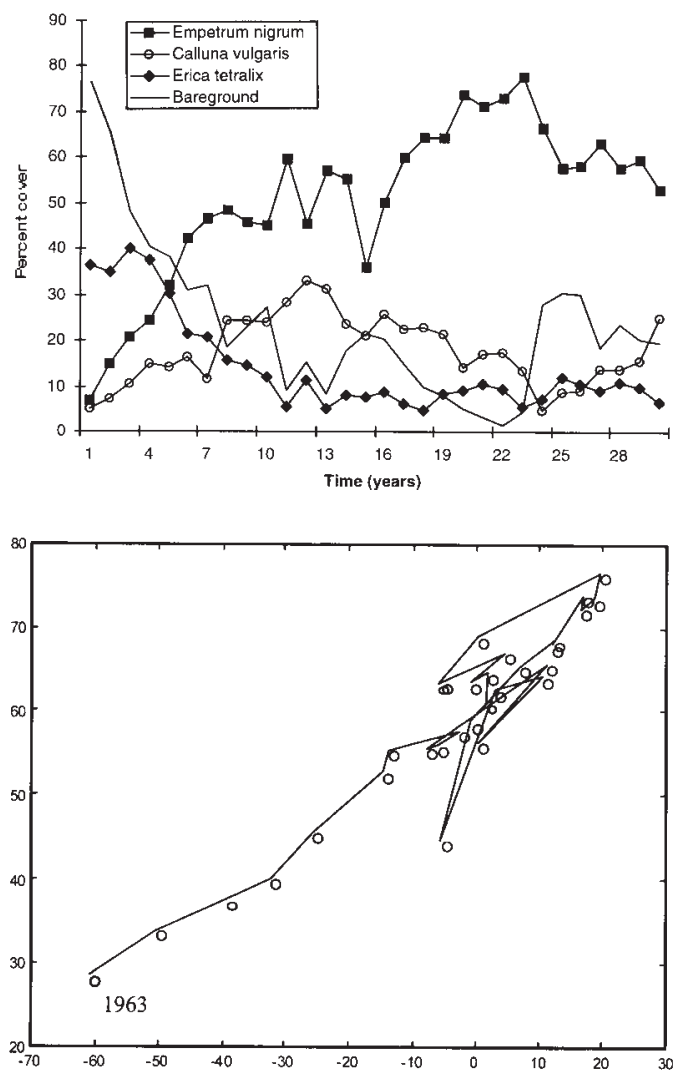

Figure 2. Global pattern of heathland at the species (top) and community (bottom) level. In the latter, the space is defined by the first two principal components which capture $80 \%$ of total variation. A point represents the community state at 1 year. The recovery process begins (1963) in the lower left quadrant of phase space. The dynamics here is not clearly related to any one species, but rather emerges from pair-wise associations. 


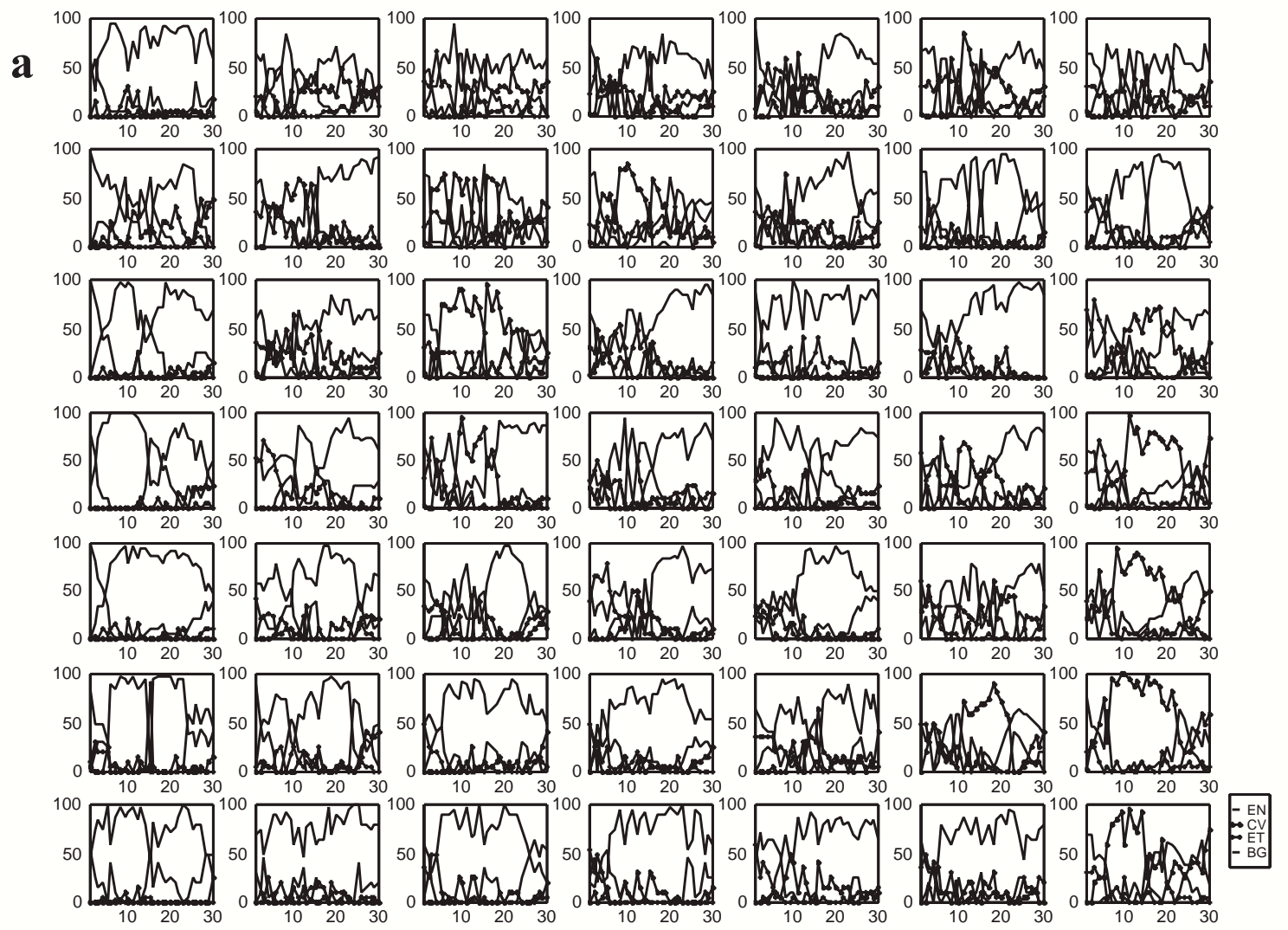

b

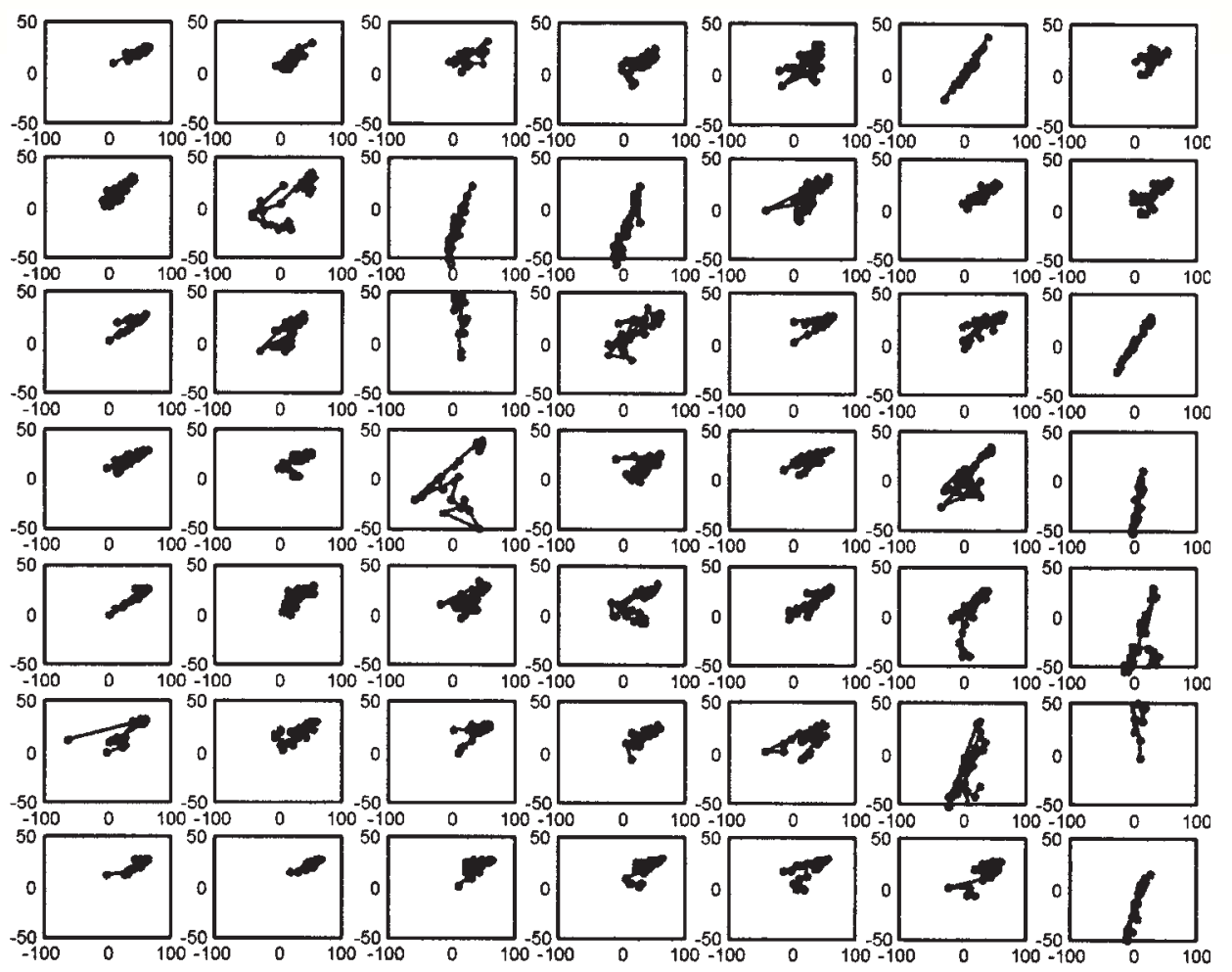

Figure 3. Species (a) and community (b) level dynamics within the cells of a $7 \mathrm{~m} \mathrm{x} 7 \mathrm{~m}$ subspace. The abbreviations are as follows: Empetrum nigrum (EN), Calluna vulgaris (CV), Erica tetralix (ET) and bare ground (BG). 
occur. One explanation is that high initial abundance of Calluna seedlings and absence or very low abundance of Calluna seedlings significantly affects the competitive relationship between species. This has been demonstrated in simulation studies (Heil and Bobbink 1993).

Figure $3 \mathrm{~b}$ shows the corresponding community-level dynamics (first two principal component axes). Many areas (e.g., cells 1, 43) remain fairly static, being dominated by Empetrum from beginning to end. In cells with considerable dynamics (i.e., trajectories widely spanning PCA space), all extremes in behaviour are seen. In some cases, (e.g., cells 6, 21) dynamics is overwhelmingly linear. In these cells, the recovery process begins in the lower left area of the cell and ends in the upper right. Interestingly, the linear pattern here emerged not just from simultaneous monotonic species response (as we would expect if the process followed a homogeneous Markov chain), but from a clear sequence of species-turnover (see also Figure $3 a)$. In other cases (e.g., cells 18, 24), dynamics is overwhelmingly noisy at both the species and community lev- els. A few trajectories showed transient behaviour (e.g., cell 27 ) in which the early phase is noisy and the later phase linear.

Figure 4 displays the transition matrices for each cell. In general, the highest transition probabilities occur on the diagonal. This reflects a very strong self-replacement between years, which is to be expected of perennial species. Bare ground has a consistently high replacement probability, suggesting that disturbance plays a significant role in dynamics. The difference among cells in their speciesreplacement probabilities (non-diagonal values) were sufficient to represent dramatic differences in dynamics (Figure $3 b)$.

Figure 5 shows the corresponding phase space plots. Most cells converged to an attractor region, i.e., dynamics became concentrated in a subset of phase space. Interestingly, cells which appear noisy in PCA space often show a distinct pattern in phase space, represented by slow initial dynamics and then rapid convergence to a cyclical
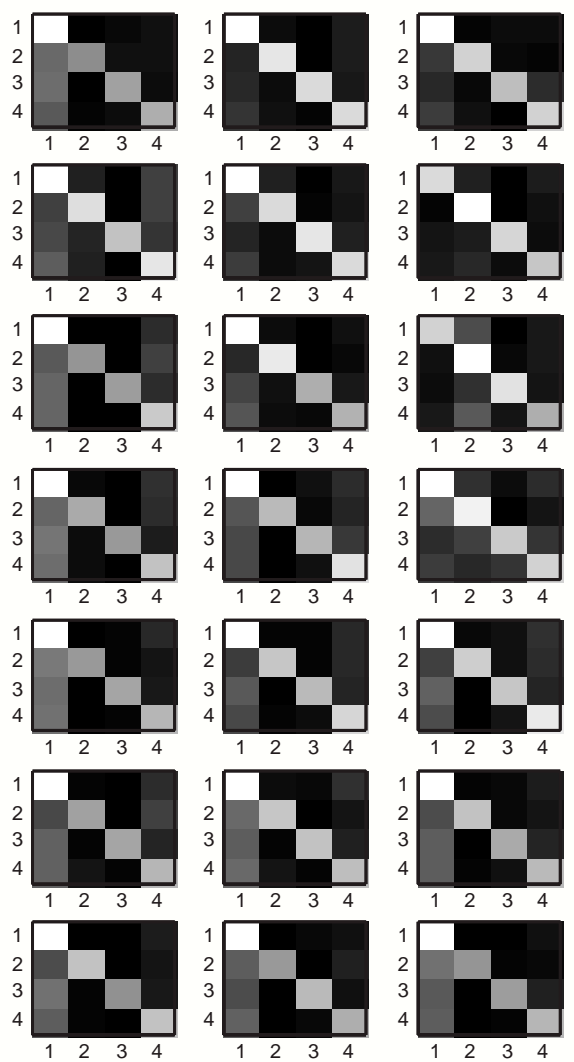
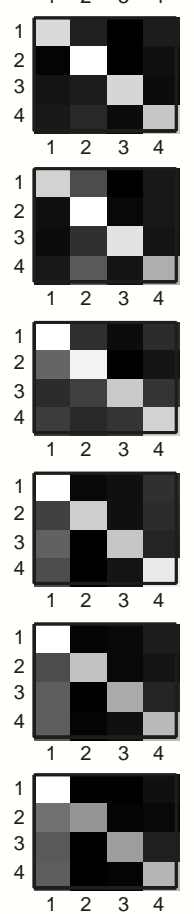
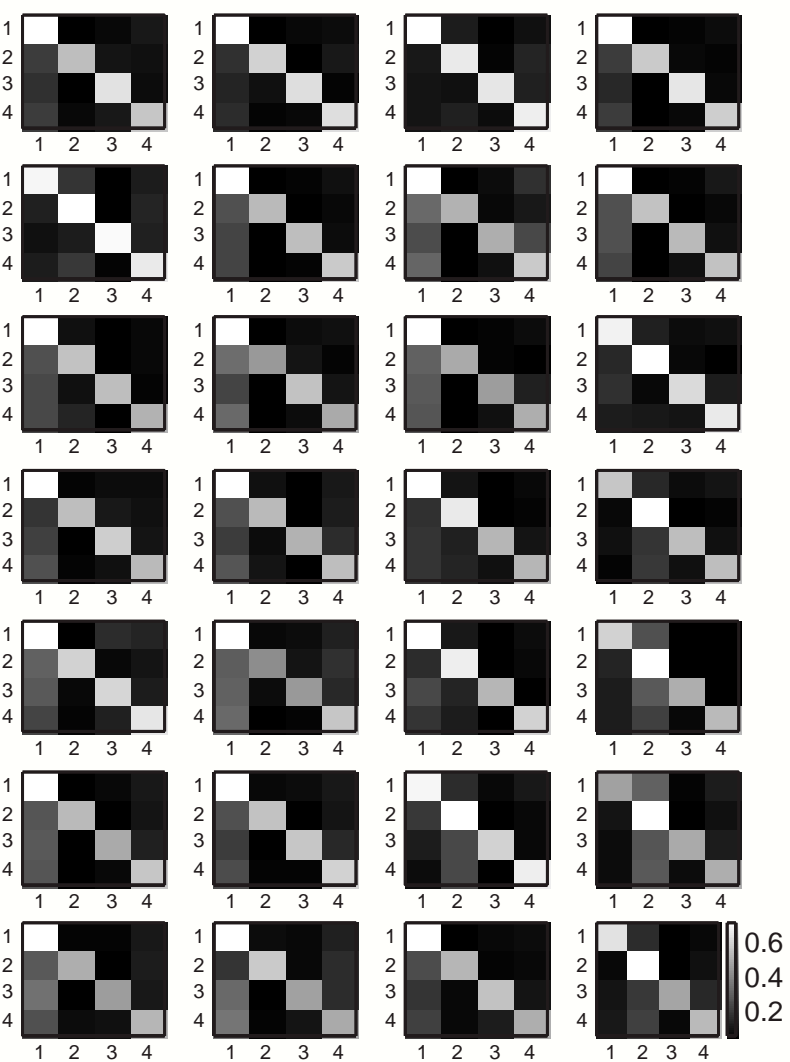

Figure 4. Transition matrices of cells in a $7 \mathrm{~m} \times 7 \mathrm{~m}$ subspace. Transition probabilities are calculated according to Orlóci et. al. (1993). The columns represent gains and the rows, losses. The order of species along columns or rows is: 1. Empetrum nigrum 2. Calluna vulgaris 3. Erica tetralix 4. Bare ground. Magnitude of probabilities range from 0 (black) to 0.8 (white). 
Table 1. Relationship between initial condition and final state. This is determined by following the fate of pair-wise trajectories whose initial states are close or far in the phase space of Fig. 3b. The elements of the table represent the proportion of times a case was observed.

\begin{tabular}{ccc}
\hline initial conditions & close & far \\
\hline close & 0.246 & 0.205 \\
far & 0.236 & 0.314 \\
\hline
\end{tabular}

attractor. Cells which appear linear in the PCA space in fact show much less directional convergence in the phase space. Furthermore, there is no relationship between initial and final condition (Table 1).

\section{Discussion}

Clearly, scale affects our perception of vegetation pattern, process and mechanism (Anand 1994), and this has been shown repeatedly in case studies. Some authors (e.g., Palmer 1988) have gone so far as to suggest that the vegetation system is fractal (sensu Mandelbrot 1983), and that new and different information is to be gained at every scale (level of observation). However, what has rarely been shown is the connections among the information gained at different levels of observation. Allen and Starr (1982) suggest that in order to understand a system at some level of observation, we must be able to observe it at another level. We found that by considering fine scales in the analysis of a recovery process, we were better able to tease apart the phases in the recovery process.
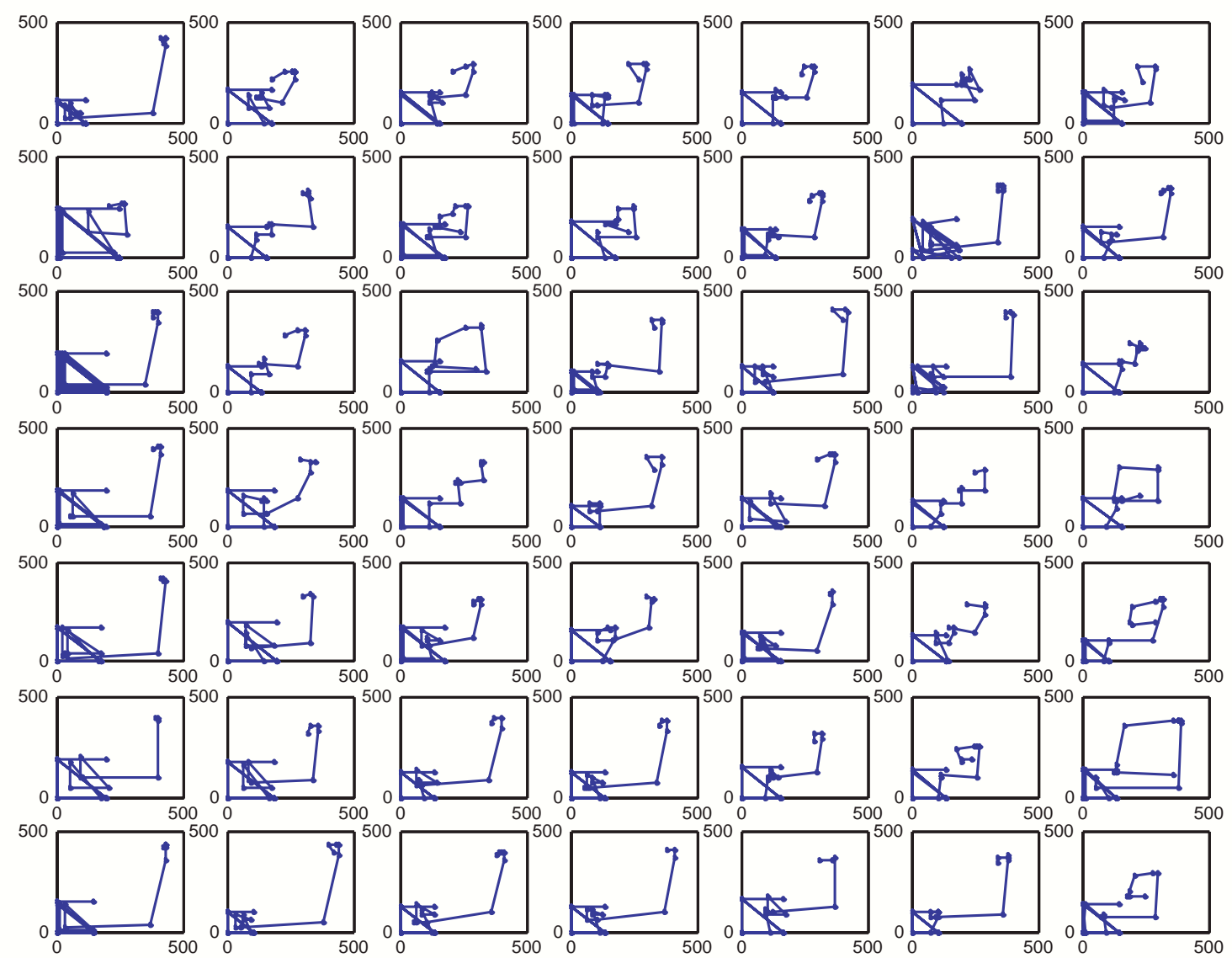

Figure 5. Phase space plot of the recovery process in a $7 \mathrm{~m} \times 7 \mathrm{~m}$ subspace. Points are Euclidean distances measured between temporal coenostates. The starting point for trajectories is generally near the middle to upper right area of phase space and the ending point in the bottom left area of phase space. Most trajectories show initial rapid movement and then slowing down to a cyclical attractor. 
At the fine spatial scale, the linear recovery process in PCA space was identified as a particular species-replacement succession in which the heathland community was initially dominated by Erica tetralix then by Calluna vulgaris, and finally by Empetrum nigrum. This observation corresponds well to the findings of Prentice et. al. (1987), whose simulation studies were based solely on simple species morphological and life-history characteristics. They found that Erica behaved as an "early-successional species and later as a fugitive opportunist". They hypothesized that Calluna has a high establishment rate, but, this was not observed in the data. They attributed the overtaking of Erica by Calluna to the fact that Calluna bushes grow slowly and are larger than those of Erica. Interestingly, they showed that if Erica establishes itself at sufficient density, it can 'protect' Calluna from competition by Empetrum. The eventual dominance by Empetrum was attributed to its fast growth rate and prostrate form, which allow individuals to grow large and eventually dominate the system in the absence of disturbance.

Prentice et al. (1987) claim that these simple mechanisms are sufficient to explain the compositional dynamics of the community. However, our analysis of the empirical data suggests that this is not the case at all, because at fine spatial scales (the level at which individuals are interacting and the level at which their model is constructed), considerable noise was observed. These correspond to apparently random (individualistic) specieslevel dynamics, placing importance not on a priori competitive hierarchies, but on context-dependent species interactions. The obvious question that emerges from these observations is: can the nature of dynamics (i.e., deterministic or noisy) be related to any simple rule?

Anand and Orlóci (1997) suggested that the global pattern of phase transition from determinism to apparent noise could be explained, in the long-term, by a specific combination of deterministic and random processes, i.e., the stationary Markov Chain plus quasi-random perturbation. In this chaos-theoretical model, at some critical point dynamics dramatically changed from linear to chaotic suggesting sensitive dependence on initial conditions. While we could not use chaos-theoretical diagnostic tools (e.g., the Lyapunov exponent) since there are too few data points, a simple analysis revealed that there was no relationship between the distance of an initial state and a final state. Phase space plots of the empirical data indicate that this attractor region is characterized by cycles and apparently random behaviour. The latter supports the claim that regardless of initial condition, the recovery process generally moves towards a 'strange attractor', in which movement is constrained to some defined range of phase space.

Anand and Orlóci (1997) suggested that interactions between species should increase as bare ground decreases during the recovery process. In the early phase of recovery, the dynamics should be quite straightforward since bare ground is high and interactions between species are low (i.e., the superior competitor rules). Over time, more space becomes filled and species begin to interact more closely. It is the outcome of these interactions which becomes unpredictable and is reflected as noise. Looking at fine spatial scales allowed us to examine this hypothesis in more detail. We would expect that cells showing highly deterministic dynamics should correspond to areas where bare ground is not a limiting resource. Indeed, in these cells the probability of bare ground replacing itself was particularly high. We would also expect that in cells showing noisy dynamics, bare ground would be more limiting. While this was the case most of the time, several highly noisy cells showed a high replacement probability of bare ground. These cases may be related to significant disturbance events such as sheep grazing, heather beetle infestation, and natural gap dynamics of the vegetation (Lippe et al. 1985).

The results presented here provide some evidence for two recent simple theoretical arguments regarding the importance of scale and spatial heterogeneity in plant communities. Tilman (1994) proposed a model, which he called the 'spatial competition' hypothesis, which suggests that species can coexist in an area if there is spatial subdivision of habitats. He suggested that the maintainence of diversity does not require large-scale disturbances, but could occur through plant-by-plant replacement on a local scale through the competitive ability versus colonization mechanism. Our results show that Empetrum germinates mainly once (immediately following a burn) but becomes the dominant species through vegetative expansion. However, it never completely dominates the study area. Erica, a competitive subordinate, persists in the plot by seed germination and establishment of new individuals, while Calluna, an intermediate ranked competitor, does so both by vegetative expansion and seedlings. To our best knowledge, this study is the first to report support from empirical data of Tilman's theory.

Very recently, Petraitis and Latham (1999) emphasized the importance of scale and disturbance in the origin and persistence of alternative community assemblages. They state that "in theory, a switch between states occurs when there is a change in species densities that perturbs one assemblage far enough off its equilibrium point that 
the perturbed assemblage is now in the basin of attraction of the equilibrium point of an alternative assemblage". They suggest that this can occur in two ways - once through the 'natural' process of succession, and the other through a major disturbance event. Our results nicely distinguish these two cases.

\section{Concluding remarks}

The recovery process in plant communities is both deterministic and individualistic. At a given scale, the process can appear consistently linear in some places and completely noisy in others. However, the dynamical behaviour remains rather consistent, beginning with fast directional initial dynamics followed by convergence to a cyclical or aperiodic attractor. That patterns and processes are scale-dependent is certainly not new to the field of vegetation ecology. However, the nature of this scale-dependence or 'scaling' is poorly understood. Here, we use empirical data to demonstrate that a process at a lower hierarchical level (finer spatial scale) can help in understanding the dynamics at a higher hierarchical level. The value of long-term studies that allow for spatial analyses is undeniable. Future work will be directed towards a theoretical framework for 'scaling' and 'phase transitions', an approach which we believe is promising for ecology.

Acknowledgements: We thank Jacques de Smidt for access to his data and fruitful discussions, and Klaske de Graaf for data collection. This research was conducted while M.A. was a visiting researcher at Utrecht University and funded by the Natural Sciences and Research Council of Canada (M.A.) and the Utrecht University (G.W.H.). We thank I. Scheuring and one anonymous reviewer for helpful comments.

\section{References}

Aerts, R. and G.W Heil. 1993. Heathlands: Patterns and Processes in a Changing Environment. Kluwer Academic Publishers, The Hague.

Allen, T.F.H. and T. B. Starr. 1982. Hierarchy: Perspectives for Ecological Complexity. University of Chicago Press, Chicago.

Anand, M. 1994. Pattern, process and mechanism - fundamentals of scientific inquiry applied to vegetation science. Coenoses 9: 8192.

Anand, M. and L. Orlóci. 1997. Chaotic dynamics in a multispecies community. Ecological and Environmental Statistics 4: 337344 .

Bascompte, J. and R. V. Solé. 1998. Modeling Spatiotemporal Dynamics in Ecology. Springer-Verlag, Berlin.
Clements, F.E. 1916. Plant Succession: an Analysis of the Development of Vegetation. Publ. No. 242. Carnegie Institution, Washington.

Connell, J.H. and R.O. Slayter. 1977. Mechanisms of succession in natural communities and their role in community stability and organization. American Naturalist 111:1119-1144.

Czárán, T. and S. Bartha. 1995. Spatiotemporal dynamic models of plant populations and communities. Trends in Ecology and Evolution 7: 38-42.

de Smidt, J. T. 1977. Heathland vegetation in the Netherlands. Phytocoenologia 4: 258-316.

Deutschman, D. H., S.A. Levin, C. Devine and L. A. Buttel. 1997. Scaling from trees to forests: analysis of a complex simulation model. Science Online (www.sciencemag.org).

Gimingham, C. H. 1972. Ecology of Heathlands. Chapman and Hall, London.

Gleason, H.A. 1926. The individualistic concept of the plant association. Bulletin of the Torrey Botanical Club 53: 7-26.

Heil, G.W. and R. Bobbink. 1993. "Calluna", a simulation model for evaluation of impacts of atmospheric nitrogen deposition on dry heathlands. Ecol. Modelling 68: 161-182

Lippe, E., J.T. de Smidt and D.C. Glenn-Lewin. 1985. Markov models and succession: a test from a heathland in the Netherlands. $J$. Ecol. 73: 775-791.

Lorenz, E.N. 1963. Deterministic nonperiodic flow. J. Atm. Sci. 20: 130-141.

Mandelbrot, B. B. 1983. The Fractal Geometry of Nature. W. H. Freeman and Company, New York.

Orlóci, L., M. Anand and X. S. He. 1993. Markov chain: a realistic model for temporal coenosere? Biométrie-Praximétrie 33:7-26.

Palmer, M.W. 1988. Fractal geometry: a tool for describing spatial pattern of plant communities. Vegetatio 75: 91-102.

Petraitis, P. S. and R.E. Latham. 1999. The importance of scale in testing the origins of alternative community states. Ecology 80 : 429-442.

Pillar, V. De P. and L. Orlóci. 1996. On randomization testing in vegetation science: multifactor comparisons of relevé groups. $J$. Veg. Sci. 7: 585-592.

Prentice, I.C., O. van Tongeren and J.T. de Smidt. 1987. Simulation of heathland vegetation dynamics. J. Ecol. 75: 203-219.

Rosen, R. 1970. Dynamical System Theory in Biology. Wiley-Interscience, New York.

Tilman, D. 1994. Competition and biodiversity in spatially structured habitats. Ecology 75:2-16.

Tilman, D. and P. Kareiva. 1997. Spatial Ecology. Princeton University Press, Princeton, New Jersey.

van der Maarel, E. 1996. Pattern and process in the plant community: fifty years after A. S. Watt. J. Veg. Sci. 7: 19-28.

Watt, A.S. 1947. Pattern and process in the plant community. J. Ecol. 35:1-22. 